\title{
INTERVENCIÓN Y DESTRUCCIÓN DE MONUMENTOS PÚBLICOS EN AMÉRICA LATINA COMO RESPUESTA ANTE EL DOMINIO CULTURAL E IDEOLÓGICO DEL ESPACIO PÚBLICO
}

\author{
INTERVENTION AND DESTRUCTION OF PUBLIC MONUMENTS IN LATIN \\ AMERICA AS A RESPONSE TO THE CULTURAL AND IDEOLOGICAL DOMAIN OF \\ THE PUBLIC SPACE
}

\author{
JONATHAN LUKINOVIC HEVIA (IDEA-USACH) \\ Instituto de Estudios Avanzados IDEA \\ Universidad de Santiago de Chile. \\ Santiago de Chile, Chile \\ jonathanlukinovic@,hotmail.com
}

\section{Resumen:}

La presente propuesta apunta a reconocer algunos de los mecanismos que articulan los actos de desmonumentalización, intervención y destrucción contemporánea de monumentos públicos en Latinoamérica, con énfasis en ciertas manifestaciones en que los ciudadanos debieron configurar y resignificar herramientas ante las limitantes de contextos represivos o de escasa participación ciudadana y los símbolos impuestos en dichos contextos. Ante dichas transformaciones, buscamos también reconocer las adaptaciones de las herramientas teóricas que permiten una mejor comprensión, relación e inclusión de los actos de intervención y destrucción de monumentos públicos, principalmente de aquellos que tienden a ser catalogados como vandalismo y enjuiciados, siendo relegados a simples actos destructivos.

Palabras Clave: Monumentos - Intervención -Destrucción - Iconoclasia - Vandalismo

\begin{abstract}
:
The present proposal aims to recognize some of the mechanisms that articulate the acts of dismonumentalization, intervention and contemporary destruction of public monuments in Latin America, with emphasis on certain manifestations in which citizens had to configure and resignify tools due to limitations of repressive contexts or of low citizen participation and the symbols imposed in those contexts. Given these transformations, we also seek to recognize the adaptations of the theoretical tools that allow a better understanding, relationship and inclusion of acts of intervention and destruction of public monuments, mainly those who tend to be classified as vandalism and prosecuted, being relegated to simple destructive acts.
\end{abstract}

Keywords: Monuments - Intervention - Destruction - Iconoclasm - Vandalism 


\title{
INTERVENCIÓN Y DESTRUCCIÓN DE MONUMENTOS PÚBLICOS EN AMÉRICA LATINA COMO RESPUESTA ANTE EL DOMINIO CULTURAL E IDEOLÓGICO DEL ESPACIO PÚBLICO
}

\author{
Dr. JONATHAN LUKINOVIC HEVIA (IDEA-USACH)
}

jonathanlukinovic@hotmail.com

\section{Introducción}

Por todo el orbe se erigen un sinnúmero de monumentos que intentan rememorar el pasado, bustos de personajes supuestamente célebres en la conformación de una sociedad, o esculturas representativas de hitos importantes en el surgimiento de estas y en el establecimiento de la realidad en que hoy se inscriben las diferentes comunidades. En lo cotidiano, estos monumentos parecieran integrarse inocentemente con su entorno, formando parte del día a día de las personas, pasando en ocasiones desapercibido lo rememorado, siendo valorados y apreciados de diferentes maneras por los habitantes de estos espacios, adquiriendo significaciones que van desde la identificación a la indiferencia o incluso el rechazo, dependiendo del tipo de vínculo que el sujeto o comunidad tenga con la figura histórica rememorada, o con quien decide rememorar valiéndose del acto y discurso monumental. Acto mediante el cual se instaura, en el presente, una perspectiva histórica particular, que puede ser considerada como vencedora, en la medida que logra imponerse, e imponer a sus héroes e ideas sobre otros discursos silenciados. De esta manera obtiene un lugar físico y reconocible como centro o eje de relación para la ciudadanía, adquiriendo, por el simple hecho de su materialización en el presente de inscripción, un lugar de prestigio que lo valida como referente a través de los recursos y posibilidades oficiales y legales de monumentalización.

La apropiación del espacio, reconocida en el acto monumental, como materialización de un discurso que no permite naturalmente instancias de diálogo una vez que es instaurado, la oficialización de unos discursos en desmedro de otros, la erradicación o desplazamiento oficial de algunos monumentos y la vandalización, intervención o destrucción de otros, dan cuenta en parte de la pugna existente por la dominación histórica e ideológica del espacio público, la cual podemos reconocer en diversos momentos de la historia latinoamericana. Momentos en que perspectivas históricas, políticas y sociales opuestas, llegan a converger en torno a objetos de arte y monumentos públicos, tornándose estos en puntos críticos de relación entre la ciudadanía y el espacio que habitan. Aspecto que se posibilita en la medida que reconocen en dichas figuras la representación positiva de su pasado directo y formativo, la carencia absoluta de representación en el espacio habitado, o incluso, la instauración de referentes que aluden a figuras opuestas y disruptivas a sus intereses e historia. Lo que lleva a estos objetos de arte, esculturas y monumentos públicos, a ser susceptibles a transformaciones que buscan validar, dislocar, descentrar, transformar o erradicar el sentido de lo representado.

Estas formas de relación con los monumentos, suceden tanto al margen como dentro de las dinámicas sociales y culturales, por medio de acciones -o inacciones- ordenanzas, reformas y legislaciones referentes al espacio público por un lado; las que transforman, desplazan, descuidan o destruyen los monumentos en medida que poseen herramientas oficiales para ello, y por el otro lado, 
en manifestaciones ciudadanas y relaciones cotidianas de los sujetos con su entorno, sumado a ciertos hechos, acciones o intervenciones en que se busca destruir o transformar el sentido de estos.

Si bien las manifestaciones en torno a monumentos públicos es posible reconocerlas en todo el mundo, sobre todo en situaciones de conflictos cívicos o militares, en Latinoamérica se presenta una cantidad considerable de manifestaciones de monumentalización y desmonumentalización en todas sus vertientes, incluso en momentos no evidentemente críticos. Según los casos iniciales recopilados, esto tendría explicación en la cercana relación temporal existente entre los monumentos construidos y el pasado rememorado, lo que genera situaciones críticas con la presencia de estos en el contexto urbano. En una primera incursión a través de medios de comunicación digitales e impresos, en países latinoamericanos, solo en el periodo del año 2000 hasta mediados del 2019, pudimos reconocer la cantidad de 130 casos, cifra que se vio doblada con el caso chileno desde octubre del mismo año, en la que contabilizamos alrededor de 200 casos en un periodo de cinco meses. Si bien no profundizaremos en esta ocasión en todos los casos señalados, nos centraremos en esbozar y relacionar algunas categorías que permitan el manejo de un fenómeno que se articula en relación con mecanismos similares en nuestro continente, para lo cual utilizaremos algunos casos a modo de ejemplo, centrándonos en las intervenciones realizadas, independientemente del tiempo y lugar en que fueron ejecutadas, con miras a lograr un análisis más amplio.

Para lograr este cometido hemos determinado dos ejes principales, relacionados con su carácter oficial y no oficial. Por el lado de las manifestaciones consideradas como oficiales hemos catalogado; monumentos erradicados, propuestas gubernamentales de monumentalización y desmonumentalización y monumentos olvidados o deteriorados. Por el lado de las manifestaciones no oficiales tenemos monumentos destruidos, rayados, intervenidos y atentados a algunos monumentos. Estos casos de estudio, agrupados en dichas categorías, sin considerar inicialmente el país donde suceden, atendiendo a sus características y mecanismos, nos permitieron vislumbrar la existencia de un fenómeno no aislado ni único, reconocible incluso como práctica recurrente, tanto en lo cotidiano, por el lado de las manifestaciones oficiales, como en situaciones levemente disruptivas o en momentos álgidos de conflicto social, por el lado de las respuestas ciudadanas.

En este sentido, expondremos en estas páginas dos focos de tensión; por un lado, en cuanto a manifestaciones oficiales, reconocemos la constante batalla por instaurar ciertos monumentos o discursos y erradicar otros, ejercicio que apunta a validar y negar perspectivas históricas y sus referentes en el espacio urbano. Y por el otro lado, al margen de lo oficial y lo legal, tenemos las respuestas ciudadanas, muchas veces disruptivas, frente a los discursos materializados por el primer grupo. De esta manera, es posible reconocer en ambas veredas, formas de relación entre la ciudadanía, el pasado y el contexto urbano del presente, que obedecen a mecanismos complejos en relación con las posibilidades y formas de participación que esta tiene. Formas que es necesario vislumbrar para comprender y apuntar a la democratización de la ciudad en todos sus aspectos, pues la marginación no solo se advierte en aspectos de sectorización, sino que también en aspectos simbólicos que la misma población reconoce y busca contrarrestar.

De esta manera, apuntaremos a comprender y dilucidar los diferentes mecanismos que articulan los actos de monumentalización, desmonumentalización, intervención y destrucción de monumentos públicos en países latinoamericanos en algunos momentos del siglo XXI. Lo que buscamos, como se ha expuesto, no es necesariamente trabajar un periodo concreto de tiempo, sino que apuntamos a manejar ciertas categorías que permitan romper con las clasificaciones usuales que han servido a través del tiempo para clasificar y manejar estas manifestaciones, por ello se trabajarán de modo general, atendiendo a su relación con el entorno y a los ejercicios cometidos sobre monumentos públicos, dejando de lado en parte su temporalidad y el lugar en que suceden, buscando trabajarlo 
como un fenómeno identificable a nivel latinoamericano. Este cometido se logrará atendiendo a sus formas de relación con el entorno y la cultura que les conforma, el rol que la instauración y la transformación de estos, como discurso conmemorador/educativo unidireccional y su posterior respuesta/resistencia, presentan en la sociedad que les contiene, y como, superando la materialidad estética que les conforma, se tornan herramientas de apropiación histórica, ideológica y cultural del espacio público, las que son utilizadas por diversos intereses en pugna en su instauración, y reapropiadas y resignificadas por las comunidades o espacios en que dichos monumentos se erigen.

Para lograr comprender de manera cabal la relación de estas manifestaciones artísticas con su entorno y con los ciudadanos, es importante considerar diferentes factores que se manifiestan en torno a estos, o bien considerar los elementos de base necesarios para su concretización, lo cuales les permite pasar desde el discurso histórico a inscribirse en un presente específico. En este sentido son importantes diversas configuraciones teóricas, como las trabajadas en torno a temas como memoria, monumentos, vandalismo/iconoclasia, apropiación y discurso, entre otros, las cuales permitirán esbozar una perspectiva de análisis competente de este fenómeno a nivel funcional.

\section{La memoria: el pasado y su reconfiguración}

Si hablamos de monumentos, hablamos de conmemorar, de rememorar el pasado, de validar un pasado particular por sobre otro, por lo que es importante considerar el concepto de memorias o la capacidad de memoria que los grupos humanos tienen sobre sí mismos. El rememorar los orígenes, tanto desde su concepción mítica, como de los hitos de reafirmación de su identidad, es fundamental para la conformación del presente de una comunidad, lo que "sería una de las características constitutivas de la identidad, tanto individual como colectiva". Se considera como memoria a la suma de procesos y prácticas mediante las cuales el pasado es reconstruido y recreado, lo que necesariamente implica una reelaboración, selección y jerarquización de unos momentos por sobre otros, como señala Le Goff, "lo que sobrevive no es el complejo de lo que ha existido en el pasado, sino una elección realizada por las fuerzas que operan en el desenvolverse temporal del mundo y de la humanidad", selección que debiese reflejar o comprender los elementos, intereses y perspectivas de una comunidad en el presente desde el que la memoria actúa.

El pasado es rememorado a través de diversas prácticas sociales que son "necesarias (...) para la cohesión del grupo y para la mantención de su identitario colectivo"3, recuperando y enalteciendopositiva o negativamente- elementos fundamentales en la definición de una identidad colectiva y la explicación de su presente. Elementos que implican más bien la imposición de un discurso oficial sobre uno no oficial, que el consenso colectivo sobre los hechos del pasado y la importancia que estos tienen.

Los discursos provenientes de la memoria están en constante pugna con el olvido, una lucha incansable por ocupar aquellos espacios que el olvido, compuesto por el paso del tiempo y por los silencios de los discursos imperantes del presente, han vaciado. Espacios de importancia en cuanto ayudan a la comprensión y explicación de la realidad. "En este sentido, la materialización de la memoria colectiva aparece como una lucha entre el recuerdo selectivo y el olvido institucional" 4 . Son

\footnotetext{
1 Todorov, Tzvetan, "La memoria amenazada", en Todorov, Tzvetan, Los abusos de la memoria, Barcelona, Páidos, 2000, pág 51.

2 Le Goff, Jacques, El orden de la memoria: El tiempo como imaginario, España, Editorial Paidós, 1991, pág. 227.

3 Raposo Quintana, Gabriela, "La memoria emplazada: proceso de memorialización y lugaridad en post-dictadura", Revista de Geografía Espacios, Vol. 3, N 6, Chile, 2012, pág. 65.

${ }^{4}$ Raposo Quintana, Gabriela, “La memoria emplazada...”, op. cit., pág. 78.
} 
los grupos humanos, en relación con las posibilidades de apropiación, dominio y resignificación de recursos y discursos, los que decidirán qué elementos son necesarios recordar y cuáles deben ser inscritos en el presente. Lo que nos lleva a comprender que la memoria es, en suma, una selección o determinación en que "algunos rasgos del suceso serán conservados, otros inmediata o progresivamente marginados, y luego olvidados" ${ }^{5}$ en pos de un discurso y memorias en común, "culturalmente y políticamente influyentes y hasta hegemónicas" a las que el habitante o ciudadano de un espacio/comunidad adscribirá para formar parte de esta, en la medida que se identifica y representa con un pasado en común.

Claudia Feld plantea respecto a la memoria colectiva, tres manifestaciones mediante las cuales esta se posibilita; primero una dimensión narrativa en la que se caracteriza a quien construye el relato en relación con quien lo recibe -emisor/receptor-, luego una dimensión espectacular en la que se establece una puesta en escena de lo rememorado y se materializa ese pasado, y una dimensión veritativa en que importa la concepción de verdad construida en relación con otras verdades sobre las que esta se impone. En este sentido, la memoria y el ejercicio de rememoración del pasado tendrán diferentes manifestaciones en relación con los diversos medios a través de los cuales se manifiesta, y diversas reescrituras y versiones de un mismo pasado, el "que constantemente es recreado y proyectado en los nuevos discursos" $"$.

Al hablar del pasado de una comunidad, comprendemos que tendrá tantas aristas como posturas o perspectivas -o incluso habitantes- tenga un grupo humano, pero, al hablar de discurso histórico recogido por medio de la memoria colectiva, como ya se ha esbozado, comprendemos de por sí la selección, imposición y validación de unos discursos por sobre otros, en la búsqueda de triunfalismo, glorificación y oficialización de una postura particular. Como señala Jelin "es imposible encontrar una memoria, una visión y una interpretación únicas del pasado, compartidas por toda una sociedad". En este sentido, es posible reconocer momentos o períodos históricos en los que "el consenso es mayor, en los que un libreto único de la memoria es más aceptado o hegemónico [pero] siempre habrá otras historias, otras memorias e interpretaciones alternativas" ${ }^{10}$ que serán relegadas al olvido en desmedro de "una historia idealizada, construida y reconstruida según las necesidades y al servicio del poder actual" "11, En el discurso de los vencedores siempre se plantea por sobre el de los vencidos, en la medida que dominan los recursos de inscripción y validación. De esta manera, el Poder/estado actúa mitificando a sus héroes y validando sus acciones con vista de conseguir un fin propio, que en el discurso histórico se intenta instaurar como fin común "mediante la puesta en escena de una herencia"12 determinada y construida con intereses particulares. Fenómeno en que se reconoce un "monopolio en la administración del bien común por parte del poder político"13. En

\footnotetext{
5 Todorov, Tzvetan, Los abusos de la...., op. cit., pág. 16.

' Stern, Steve, "De la memoria suelta a la memoria emblemática: hacia el recordar y el olvidar como proceso histórico (Chile, 1973-1998)", en Garcés, Mario et al. (eds.), Memoria para un nuevo siglo: Chile, miradas a la segunda mitad del siglo XX, Santiago de Chile, Ediciones LOM, 2000, pág. 13.

${ }^{7}$ Feld, Claudia, "Memoria colectiva y espacio audiovisual: historia de las imágenes del juicio a las ex juntas militares (1985-1998)", en Groppo, Bruno y Flier, Patricia (comps.), La imposibilidad del olvido. Recorridos en la memoria en Argentina, Chile y Uruguay, La Plata, Ed. Al Margen, 2001.

${ }^{8}$ Raposo Quintana, Gabriela, “La memoria emplazada...”, op. cit., pág. 66.

9 Jelin, Elizabeth, Los trabajos de la Memoria, Madrid, Editorial Siglo XXI, 2002, pág. 230.

${ }^{10}$ Jelin, Elizabeth, Los trabajos de la ..., op. cit., pág 230.

11 Balandier, George, El poder en escenas. Del la representación del poder al poder de la representación, Barcelona, Paidos, 1994, pág 19.

12 Balandier, George, Elpoder en escenas..., op. cit., pág. 19.

13 Sánchez, Mario Jordi y Aix Gracia, Francisco, "Vandalismo contra el patrimonio en las grandes ciudades" en Jornadas Repensando la metrópolis. Prácticas experimentales en torno a la construcción de nuevos derechos urbanos, Málaga, 2010, pág.11, en línea
} 
este sentido comprendemos que la instauración de un discurso oficial siempre tenderá a servir como una herramienta de validación e inscripción en la historia y en la cultura, el que por diversos medios es instaurado, superando incluso el carácter documental, intentando fusionarse con el presente de inscripción.

En este proceso, una herramienta que ha sido funcional a este propósito es el monumento, el que como mezcla de arte e historia, cargado de un discurso significativo, intentará instaurarse no solo en la historia rememorada, sino que irá más allá al materializarse en el presente y en el espacio cotidiano, siendo así un referente directo de relación entre los ciudadanos que le aprecian/leen y el significado que dicho monumento trae consigo.

\section{Monumentos y monumentalización}

Toda memoria necesita de concreción para ser percibida por una colectividad, requiere de una inscripción, "un soporte para ser materializada y comunicada"14, un soporte que permita que dicha construcción pueda ser conocida y reconocida por los sujetos que la rememoran o para quienes es rememorada, es decir un lugar de memoria. En este sentido la ciudad es el espacio ideal para evocar estos pasados condicionados, siendo "un buen escenario para presentar las marcas que hacen evocar memorias individuales y locales, que en muchos casos se forjan con visiones antagónicas"15, lo que lleva a que "parques, plazas, calles, ríos, barrios, etc., se configuren como espacios para una especie de materialización de la memoria"16 siendo por tanto susceptibles de colonización e instauración monumental, la que no necesariamente es directa o coherente con el pasado y realidad de sus habitantes en relación a lo antes visto.

El monumento se presenta como idóneo a la concretización-materialización de lo que la memoria trae al presente de modo selectivo, ocupando además un espacio privilegiado en el centro de la urbe, con el "propósito de construir una historia que luego de ser revisada se pueda sumar a la historia nacional, de manera que se constituya en el relato hegemónico" ${ }^{17}$. Como señala Le Goff, la palabra monumento se vincula con "la raíz indoeuropea men que expresa una de las funciones fundamentales de la mente (mens), la memoria (memini), el verbo monere significa «hacer recordan», de donde se deriva «avisan», «iluminar», «instruir». ${ }^{18}$ lo que establece una relación entre el recuerdo, lo rememorado, sumado a la capacidad educativa que posee y la manifestación y concretización de este en el espacio del presente. Herramienta que ha sido apropiada desde sus primeras manifestaciones por diversas formas de poder, en la medida en que el monumento sirve como herramienta de inscripción en el contexto y en el discurso histórico, dejando huellas que son reconocibles en el

en:

http://w01.centrodeestudiosandaluces.es/actividades/comunicaciones/1277978745604218610 L2 Francisco Aix.pdf, consulta: 21 de abril de 2020.

14 Bastías Sekulovic, Malena, "Del relato oficial a la recepción de los visitantes: análisis de la puesta en escena del pasado reciente en el Museo de la Memoria y de los Derechos Humanos de Chile”, en Arrieta Urtizberea, Iñaki (ed.), Lugares de memoria traumática: representaciones museográficas de conflictos políticos y armados, Bilbao, Universidad del País Vasco, 2016, pág. 203.

15 Raposo Quintana, Gabriela, “La memoria emplazada...”, op. cit., pág. 67.

16 Kingman, Eduardo y Castaño Vargas, Lina, "Significación histórica de la memoria: monumento a los estudiantes caídos en la dictadura de Rojas Pinilla, Cali 1958" en Maestría de investigación en Antropología Memoria, poder e identidad,

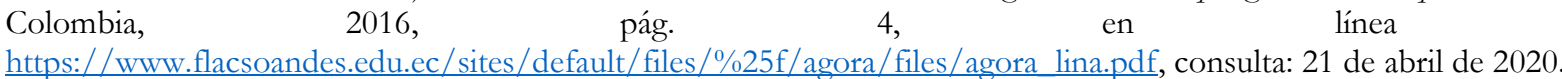

17 Martínez Montoya, Magda, Uno se muere cuando lo olvidan. La construcción de la memoria de la violencia en Colombia, Tesis de Maestría en Estudios Culturales de Pontificia Universidad Javeriana, Bogotá, 2012, pág. 21.

${ }^{18}$ Le Goff, Jacques, El orden de la memoria: El tiempo como imaginario, Barcelona, Editorial Paidós, 1991, pág. 227. 
presente y en el futuro. Como señala Salazar estos "rememoran el pasado, constituyen recuerdos, pero también tratan de imponer determinadas interpretaciones del pasado, moldear la memoria y, por tanto, construir la identidad social. Se trata de representaciones colectivas en todos los sentidos" ". Por otro lado, el monumento se establece como herramienta no solo en cuanto a rememoración natural común a todo un grupo humano, sino también de la imposición de un pasado no necesariamente rememorado, sino más bien impuesto desde una memoria por sobre otras, el que además se manifiesta a través de una estética determinada bajo el alero del arte, "lo que ha permitido su instauración exitosa en el contexto urbano a través del tiempo"20

El monumento como herramienta y manifestación política es una concepción, que si bien no está inscrita directa o necesariamente en la creación del artista o artífice que le da forma, si está presente en las motivaciones de mandantes y a los intereses $-\mathrm{y}$ discursos predominantes- de quienes encargan o determinan que se erija tal o cual representación del pasado. El monumento ha servido históricamente como "un medio privilegiado para la transmisión de mensajes ideológicos"21. Las narrativas del pasado como señala Xavier Roigé "tienen mucho que ver con los discursos políticos predominantes y satisfacen una función política doble: por un lado, legitiman los intereses sociopolíticos de los agentes que los reproducen y, por otro, refuerzan su identidad colectiva"22. Es decir, tenemos un ciclo de rearticulación constante en que interactúan por un lado, las infinitas rememoraciones del pasado, pero solo la validación e inscripción de algunas manifestaciones o concreciones de estas en el contexto público, lo que viene de paso a determinar una correcta memoria y la validez de unos recuerdos, símbolos, hitos o luchas por sobre otras. Legitimando así un orden "del presente a través de una invocación al pasado, para lo que recurre a formas estéticas poseedoras de un poderoso capital simbólico acumulado a lo largo de la historia" 23 el que, en suma, es reconocible por los sujetos en relación con otros elementos culturales comunes como educación, y un pasado ya oficializado. En este sentido "la memoria aparece como un discurso de la alteridad, en la que la posesión de una historia proporciona al grupo su identidad" 24 ya sea de modo directo o indirecto. En otras palabras, la monumentalización en la medida que idealiza lo representado, intenta establecer directrices de acción y comportamiento en cuanto se establecen como figuras, hitos o íconos situados simbólicamente en el centro de la cotidianeidad, transformándoles en figuras susceptibles de imitación, "exaltando la legitimidad de quienes ostentan el poder en el momento presente, que aparecen así como herederos naturales de las glorias del pasado" "25. Glorias que se seleccionan como válidas, como verdaderas y dignas de ser rememoradas, las que una vez instauradas, con "su presencia «naturalizada» en nuestra vida cotidiana, en los lugares centrales del espacio público, reproduce de modo sutilmente repetitivo, mediante actitudes, comportamientos y poses,

\footnotetext{
19 Salazar, Gabriel, "Memoria, hermenéutica y movimiento de la 'baja sociedad civil' (Chile sobre el 2000)”, en Garcés, Mario et al. (comp.), Memoria para un nuevo siglo. Chile, miradas a la segunda mitad del siglo XX, Santiago de Chile, LOM Ediciones, 2000, págs. 257-270; Salazar, Gabriel, La bistoria desde abajo y desde dentro, Santiago de Chile, Facultad de Artes, Universidad de Chile, 2003, pág. 71.

${ }^{20}$ Brodsky B, Ricardo, Trampas de la Memoria, Santiago de Chile, Flacso, 2018.

${ }^{21} \mathrm{Vega}$, Elo, “¿Una violencia invisible? Las mujeres en los monumentos públicos”, Boletín de Arte, N 37, Departamento de Historia del Arte, Universidad de Málaga, 2016, pág. 213.

${ }^{22}$ Roigé, Xavier, "De monumentos de piedra a patrimonio inmaterial. Estrategias políticas, museológicas y museográficas de presentación de la memoria”, en Arrieta Urtizberea, Iñaki (ed.), Lugares de memoria traumática: representaciones museográficas de conflictos politicos y armados, Bilbao, Universidad del País Vasco, 2016, pág. 24.

${ }^{23}$ Vega, Elo, “¿Una violencia invisible?..., op. cit., pág. 213.

${ }^{24}$ Roigé, Xavier, "De monumentos de piedra...”, op. cit., pág. 24.

25 Vega, Elo, “¿Una violencia invisible?..., op. cit., pág. 214.
} 
«estetizadas»" ${ }^{26}$, evocadas por aquellas figuras o discursos, que buscan la consagración publica de la idea que un personaje representa.

El que se seleccione o se monumentalice a unos símbolos por sobre otros, respaldados o no por lo histórico documental, da a entender que existe una valorización y catalogación previa, una puesta en valor por parte del Estado de determinados elementos culturales" ${ }^{27}$ los que no necesariamente se ven en la rememoración documental o en la historia oficial. Es de suponer que quienes ostenten el poder y el dominio del discurso oficial, contarán con recursos y herramientas para disponer del espacio público, e instaurar los símbolos que les sean de reconocimiento y representación directa. Es común a las construcciones sociohistóricas el rememorar y representar su pasado, a sus héroes o mártires. El problema se presenta cuando aquellos héroes y aquellos monumentos, no representan los intereses de toda la población, o no son introyectados de la manera esperada por la ciudadanía o por quienes se sitúan en la vereda de los vencidos, o bien, por quienes no reconocen un retrato o un paso coherente de la historia al monumento, o incluso por quienes reconocen una discontinuidad entre el monumento y el espacio concreto de lo público en que se inscribe.

Para evitar algunos de estos conflictos, se tiende a naturalizar la figura rememorada mediante aspectos simbólicos que destacan aspectos heroicos, humanos o sociales de las figuras históricas representadas, lo que trae consigo un "enmascaramiento de su complejidad, en aras de su simplificación y de la neutralización de sus posibles aristas conflictivas"28 -factor en que el rol del artista se vuelve fundamental en la medida que puede generar dichas transformaciones y anexar a dichas figuras un carácter menos disruptivo a través de una representación mediada-, elemento que también se logra con el descentramiento, o con la instauración de estas en otros centros urbanos en que no interactúen directamente los grupos en pugna, elemento que se ha reflejado en la monumentalización en sectores periféricos, las que van desde simples nombres de calles, poblaciones, hasta monumentos concretos.

En lo anterior se han esbozado las diversas caracterizaciones que el monumento tiene en cuanto a su instauración como discurso oficial, y a su determinado paso desde el acto de memoria y la instauración de una memoria específica. Acto que no se limita, como podría esperarse, solo a una representación histórica comprobable, sino que se pasa de la mera representación a la sobre simbolización en búsqueda de la instauración de una identidad determinada por el poder en ejercicio, fenómeno en que se advierte que "los medios no transportan la memoria pública con inocencia, sino que la configuran en su estructura y en su forma misma" ${ }^{29}$. En este sentido remitiremos ahora a un elemento fundamental para el caso del que este discurso se vale, este es la unidireccionalidad del discurso al instaurarse en el contexto público.

\section{Monumentos públicos, su incapacidad dialógica como origen del rechazo}

La incapacidad dialógica que presenta el monumento lo ofrece como un recurso sumamente efectivo en cuanto a instauración e imposición valórica e histórica dentro del contexto social, debido principalmente a que no permite discusión o transformación una vez que es erigida, "petrifica[ndo] aquello que se está conmemorando, por la inmovilidad del vaciamiento o transformación de su contenido (...) la permanencia de la piedra como monumento remite a la

\footnotetext{
${ }^{26}$ Vega, Elo, “¿Una violencia invisible?..., op. cit., pág. 213.

27 Sánchez, Mario Jordi y Aix Gracia, Francisco, "Vandalismo contra el patrimonio...”, op. cit., pág.11.

${ }^{28}$ Vega, Elo, “¿Una violencia invisible?...”, op. cit., pág. 222.

${ }^{29}$ Huyssen, Andreas, En busca del tiempo perdido. Cultura y memoria en tiempos de globalización, Buenos Aires, Fondo de Cultura Económica, 2007, pág. 26.
} 
intencionalidad de repetir aquello que ha sido memorizado"30 estableciendo un discurso único y fijo que se contrapone a las prácticas de conmemoración natural resultantes "de tantas diversas prácticas de conmemoración, como posibles memorias y grupos humanos se distinguen" 31 en las que la instauración de referentes tiene un carácter quizás más momentáneo, pero que poseen una capacidad mayor de adaptación y transformación a los intereses de una comunidad. De esta forma, manifestaciones, conmemoraciones, murales, entre otros, se tornan de cierta manera formas de monumentalización de resistencia, que tienen como soporte principal la memoria, desde el presente de inscripción y que perduran mientras existan sujetos que puedan completar el carácter simbólico de lo rememorado y por lo tanto validar su inscripción en el espacio público.

Ante la unidireccionalidad del monumento y la apropiación del espacio público de la que se vale para existir, se destacan algunas opciones de relación con estos símbolos, una, es la aceptación del monumento y la naturalización de su figura en lo cotidiano, -la que puede ser sumamente válida como referente o sumamente insignificante en medida que pasa el tiempo-, por otro lado, tenemos el rechazo absoluto a las formas, personajes, valores e historia monumentalizadas, y a las figuras de poder que las erigen. Rechazo que buscará diferentes formas de manifestación para sobrellevar la unidireccionalidad del monumento y la reapropiación de los espacios en que estos se erigen. Rechazo que se comprenderá en parte por medio de la relación iconoclasia/vandalismo. Antes de avanzar, es necesario comprender, a modo de síntesis, que el poder que erige un monumento también tiene la capacidad oficial de suprimir otros que le parezca indiferentes, fenómeno que se manifiesta de diferentes maneras, que van desde la prohibición, pasando por la no mantención/olvido, hasta la directa destrucción de conmemoraciones que no estén en línea con el discurso e historia oficial rememorada. Asimismo, el dominio del discurso, de los medios y de la opinión pública, permitirán la clasificación de vandalismo para aquellas destrucciones carentes de estatus oficial.

\section{Iconoclasia y vandalismo}

Al hablar de monumentos hacemos referencia a una manifestación del arte que se instaura, la mayoría de las veces, en un espacio público. La relación del sujeto con el monumento, como hemos planteado, debido a su mensaje unidireccional y no dialógico, se dará de diferentes maneras dependiendo de la percepción, comprensión y aceptación que tenga, tanto de quienes rememoran, como de lo rememorado, e incluso el lugar en que se expone dicha rememoración. Así podremos reconocer posturas de aceptación, indiferencia, apoyo o rechazo, del cual el último, en sus manifestaciones más radicalizadas, tiende a manifestarse en actos que atentan contra la integridad de dichos monumentos. Manifestaciones que tendrán diferentes percepciones/justificaciones dependiendo de la vereda desde las que se le mire. Así, se podrán clasificar las formas de destrucción, en un intento por explicar las motivaciones y comportamientos que llevan a los ciudadanos, o grupos sociales, a desenvolverse de modo crítico en relación con una manifestación estética de un pasado específico rememorado.

En este sentido, se presenta una concepción dual que ha servido al intento de clasificar los ataques al arte. La clasificación de iconoclasia por un lado y vandalismo por el otro, servirá además de herramienta para enaltecer o quitar importancia al trasfondo de la fuerza ejercida sobre el arte público.

30 Raposo Quintana, Gabriela, "La memoria emplazada...”, op. cit., págs. 68-69.

${ }^{31}$ Raposo Quintana, Gabriela, “La memoria emplazada...”, op. cit., pág. 67. 
La iconoclasia es concebida, como hemos visto anteriormente, como la destrucción de imágenes y la destrucción de íconos. En cuanto al significado, no tiene mayor carga que el acto de destruir algo material representativo o que acarrea consigo un significado determinado. Pero si comprendemos que la idea que trae consigo dicho ícono, es reflejo de un consenso histórico o religioso, comprenderemos que el acto de la destrucción no atenta solo con la materialidad de la idea, sino con la idea misma. El origen de la iconoclasia tiene su base en la religión, en el que justificado por las escrituras, apuntaba a la liberación de la idolatraría en medida que les alejaba del camino de lo divino, por medio de "la destrucción de imágenes religiosas y la oposición al uso religioso de imágenes" 32 , las que, como representaciones humanas, como resignificaciones de otros pasados y referentes, otorgaban una carga de sentido doble que fue utilizada como recurso de reafirmación del poder, en la medida que apelaba a lo divino a través de figuras reconocibles en el curso histórico.

En adelante, en la medida que el pensamiento humano fue abriéndose a perspectivas de relación fuera de lo religioso, la iconoclasia fue mutando y pasó a "denotar, literalmente, la destrucción de cualesquiera imágenes y obras de arte y la oposición a ellas" y, metafóricamente, el hecho de "atacar o derrocar instituciones veneradas y preciadas creencias, tenidas por falaces o supersticiosas" "33. En ambas concepciones de la iconoclasia, tanto en la religiosa como en la apertura de esta, se reconoce una intencionalidad determinada por una idea, o propuesta o ideología de fondo, por lo que puede incluso acarrear consigo "una intensión, a veces una doctrina" ${ }^{34}$ como explicación o argumento al acto de destrucción. Elemento que se torna importante al caso presente, pues será esta doctrina de fondo, las intenciones y la validación de estas, las que permitirán su justificación. Si bien la caracterización de la iconoclasia no acarrea consigo necesariamente una validación que justifique sus actos, es en la compresión y esbozo de un trasfondo ideológico, lo que lo valida y sitúa en el camino de lo correcto o realizable. En otras palabras, será necesario para la iconoclasia un discurso reconocible de validación, explicación con fuertes nexos en la cultura o en el discurso oficial, la que podrá dar pie y fundamento a sus actos. En este sentido, la iconoclasia tiene "la ventaja de dar a entender que las acciones o actitudes así designadas tienen un sentido"35 particular o que al menos pueden ser desplazados a un punto de neutralidad o ser dotados "-al menos en el sentido metafóricocon la aprobación" 36 .

En oposición a la iconoclasia, o mejor aún, en ausencia de un discurso de trasfondo válido que le justifique, se presenta el vandalismo, concepto que antes hemos esbozado. El concepto de "vandalismo" tiene su origen en la necesidad de protección del arte durante el proceso de la revolución francesa, nombrado en relación -y rememoración- al saqueo de Roma por parte de los Vándalos en el año 435. Si bien ambas manifestaciones históricas tuvieron justificación o razones para las determinadas destrucciones, es en el alejamiento de lo correcto, según el discurso o perspectiva oficial, donde se distancia y clasifica como negativo, en todo término, sin dar espacio a justificación reconocible o susceptible de validación. Elemento que ya nos sitúa en relación a que el dominio discursivo es un tema fundamental a estos casos.

De esta manera la concepción de vandalismo "pasó de significar la destrucción de obras de arte y monumentos, a la de cualesquiera objetos en tanto se pudiera denunciar como trato bárbaro,

32 Gamboni, Darío, Teorías y métodos. La destrucción del arte. Iconoclasia y vandalismo desde la Revolución francesa, Madrid, Cátedra, 2014, pág. 27.

33 Gamboni, Darío, Teorías y métodos..., op. cit., págs. 27-28.

34 Gamboni, Darío, Teorías y métodos..., op. cit., pág. 28.

35 Gamboni, Darío, Teorías y métodos..., op. cit., págs. 29.

${ }^{36}$ Gamboni, Darío, Teorías y métodos..., op. cit., pág. 28. 
ignorante o inartístico desprovisto de sentido" ${ }^{37}$, definición que será competente hasta el día de hoy en relación con la destrucción de monumentos, siendo el vandalismo y el vándalo en su ejercicio, conceptos que implican "ceguera, ignorancia, estupidez, bajeza y falta de gusto" ${ }^{38}$, lo que deriva, en relación a su origen y connotación, a que sea, en suma, "inadecuado para utilizarlo en un contexto científico que aspire a una interpretación" "39. Como Señalan Sánchez y Aix, el vandalismo "ha funcionado como pseudoconcepto, y ante todo como arma arrojadiza, como muletilla reinterpretable y reinterpretada, y en suma, como una acepción coral en la que han cobrado especial peso sus connotaciones legalistas" ${ }^{\prime \prime}$. En este sentido, se advierte que no hay un esfuerzo en comprender las razones, motivaciones o ejes motores de las acciones caracterizadas en el vandalismo, a diferencia de lo caracterizado en la iconoclasia, en que importa el trasfondo, el significado, representados y justificados en su destrucción simbólica. En el vandalismo en cambio, son desplazadas las motivaciones a un extremo, en el que se anula cualquier juicio crítico o motivo avalable y se realza -y comunica- solo la destrucción de lo concreto, la destrucción de la materialización de una idea, velando la destrucción del ícono a la que alude, banalizando así el acto, permitiendo por tanto su crítica negativa.

Aun cuando se pudiese simplificar la dualidad iconoclasia/vandalismo como una relación de sinonimia y antonimia, en la práctica, con los trasfondos sociales e históricos que cada uno de ellos tiene en su conformación y evolución, es posible comprender que cada uno de estos posee una fuerza motriz evidente, que en el vandalismo es irreconocible no por su ausencia, si no por su silenciamiento. Por estas razones, han surgido, desde diversas corrientes teóricas, subcategorías en el concepto de "vandalismo", de las cuales destacamos; "vandalismo ideológico", "vandalismo convencional", subdiviendo el segundo en "vandalismo adquisitivo", "vandalismo táctico" y "vandalismo vindicativo" o "vandalismo Patrimonial"41 categorías que dan cuenta de la complejidad del fenómeno y permiten de paso abarcar de modo más competente la manifestación de este y sus distintas aristas.

En relación con tema que nos convoca, es necesario destacar, como ya se ha mencionado, que en estricto rigor, a pesar de su manejo mediático, las manifestaciones de una u otra perspectiva; iconoclasia/vandalismo, no necesariamente poseen o carecen de justificaciones que les sustenten o expliquen. En la mayoría de los casos, se podrá reconocer un discurso de trasfondo que dé a entender, por lo menos las motivaciones que les mueven, y en los casos más complejos u ocultos se podrá incluso -O debiese- apelar a reconocimientos fenomenológicos, sociales o culturales para entender el motor de dichas destrucciones.

El problema, entonces, radica no en las motivaciones o justificaciones de cada cual, sino en la validación de los discursos y el reconocimiento de estos en el poder que rige el espacio en que se erige el monumento y se efectúa la destrucción. Por este motivo, conviene "interpretarlas como un ejercicio del poder sobre los actos cotidianos, lo que incluye el marco sobre el que se desenvuelven tales actos, y sobre las diversas relaciones sociales que le dan cabida" ${ }^{42}$. Así, una destrucción o ataque realizado en un contexto específico, podrá pasar del vandalismo a la iconoclasia en la medida que la comunidad que domina dicho espacio les considere como válidas y justificables, en oposición o relación con sus referentes históricos y culturales. En este sentido, "la supuesta presencia o ausencia

${ }^{37}$ Gamboni,Darío, Teorías y métodos..., op. cit., pág. 28.

38 Gamboni,Darío, Teorías y métodos..., op. cit., pág. 28.

39 Gamboni, Darío, Teorías y métodos..., op. cit., pág. 29.

40 Sánchez, Mario Jordi y Aix Gracia, Francisco, "Vandalismo contra el patrimonio...”, op. cit., pág. 4.

41 Sánchez, Mario Jordi y Aix Gracia, Francisco, "Vandalismo contra el patrimonio...", op. cit., pág. 4.

42 Sánchez, Mario Jordi y Aix Gracia, Francisco, "Vandalismo contra el patrimonio...", op. cit., pág. 4. 
de un motivo [que] es hoy la razón principal para elegir uno u otro término" como señala Gamboni $^{43}$, pierde fuerza en la medida que el acercamiento o clasificación a uno u otro extremo, dependerá, como se ha dicho, de los discursos esbozados como representación de los actos y por tanto del poder de dominio de los medios que les contienen y comunican.

En este sentido, y llevado a lo práctico, consideramos que las diversas manifestaciones en torno a monumentos públicos a nivel latinoamericano dan cuenta de la necesidad de dar respuesta a un discurso impuesto, respaldado en las regulaciones patrimoniales, que se valida a sí mismo, impidiendo el carácter dialógico o la aprobación ciudadana. Normativa que permiten que solo algunos grupos pueden ejercer dominio del espacio público por medio de la monumentalización de sus referentes, imponiendo limitaciones legales o económicas. Ante esto, ciertos grupos sociales se ven en la necesidad, como se podrá ver en los casos expuestos más adelante, según sus herramientas e intereses, de generar actos de transformación, resignificación y apropiación del discurso monumental, siendo dichos actos muchas veces minimizados y catalogados como vandalismo, relegando a hechos aislados una respuesta condicionada propia de un fenómeno social reconocible en América Latina. Dichas manifestaciones se darán en diferentes niveles e intensidad, las que en su mayoría se posibilitarán en momentos de conflictos en que se permite una interacción directa sobre los monumentos.

\section{Vandalismo y discurso oficial}

Siguiendo la línea de lo propuesto, en el planteamiento de que es la validación y oficialidad del discurso de una comunidad, la encargada de clasificar los actos de destrucción de arte público y en este caso de los monumentos, se torna necesario plantear que el vandalismo, como un fenómeno complejo, que supera la clasificación que le es propia, obecede a una serie de factores y problemas de tipo social como "la privatización de los espacios públicos, la mercantilización en los usos de lo urbano o el carácter segregador de las políticas urbanísticas"44 en la que el "vandalismo patrimonial, [se plantea como] una crítica a las formas de gobernanza mediante un ataque a sus formas de representación" (4). Los que son ocultados o velados en el concepto y reafirmados por los medios que la comunican, los que generalmente "tienden a ignorar las posibles connotaciones ideológicas de estas acciones, despachándolas rápidamente bajo el epígrafe de «vandalismo»"45.

$\mathrm{Al}$ otro extremo, mientras los actos reivindicativos de distintas tendencias políticas y grupos humanos, sobre la materialización de íconos específicos es caracterizada y enjuiciada, es posible reconocer cómo el poder, el estado, por medio de los recursos y la autovalidación frente a estos casos, suprime, transforma, traslada y destruye de diversas maneras monumentos y obras de arte, con motivos quizás no lejanos -en trasfondo- a los que motivan el vandalismo, pero si más cercanos a la oficialidad y sustentados y justificados en el discurso público. A nuestro juicio, la caracterización de iconoclasia, en los términos expresados, comprende y contiene de diversas formas ambas caras de la moneda, la destrucción oficial y el vandalismo, pero que se separan, aprueban y enjuician en su validación por medio de los recursos técnicos y legales.

\section{Vandalismo Contemporáneo}

43 Gamboni, Darío, Teorías y métodos..., op. cit., pág. 28.

44 Sánchez, Mario Jordi y Aix Gracia, Francisco, "Vandalismo contra el patrimonio...", op. cit., pág. 4.

${ }^{45}$ Vega, Elo, “¿Una violencia invisible?...”, op. cit., pág. 224. 
Para ejemplificar lo expuesto, estudiaremos brevemente algunos casos y listaremos otros para comprender la amplia presencia de este tipo de manifestaciones. Comenzaremos con la clasificación más general que hemos planteado, con algunas manifestaciones que funcionan al margen de la oficialidad e incluso de la legalidad, aquellas que intervienen o destruyen monumentos públicos y que tienden, por sus mecanismos y recursos, a ser consideradas ni siquiera como acciones de respuesta a ciertas limitaciones del espacio público, sino que directamente como vandalismo.

En este tipo de manifestaciones y acciones, cometidas por "vándalos" y clasificadas como vandalismo por los discursos y medios oficiales, generalmente se pasan por alto las limitantes que las posibilitan, las intenciones y la comprensión icónica que las motivan, los recursos que utilizan y la resignificación que el monumento experimenta una vez que se realiza el cambio, el que, dicho sea de paso, otorga información fundamental sobre estas posturas críticas.

Estas manifestaciones, a primeras luces, se advierten como no articuladas, pero un análisis que considere el contexto de ejecución, el ejecutante, la figura representada y su incidencia histórica en el contexto -sumado a la transformación realizada-, posibilitará el estudio y la discusión sobre el rol, la importancia, el simbolismo y la significación que dichos monumentos, y las respectivas intervenciones sobre estos, tienen en el contexto latinoamericano actual. Manifestaciones que están a la par de las transformaciones sociales y urbanas, en que los ciudadanos buscan, en la medida de sus posibilidades, ser partícipes de su entorno y de generar cambios que permitan la actualización y resignificación de referentes, en pos del reconocimiento de sí mismos y de sus comunidades en el espacio que habitan. Fenómeno que se posibilita en la medida que se reconoce una suerte de desactivación simbólica del monumento, que manifiesta la pérdida de sentido que este tiene en cierto momento para la comunidad en la que fue instaurado.

El vandalismo, como hemos visto, tanto concepto como recurso, tiende a estar marcado y estigmatizado por la oficialidad como una manifestación que carece de un discurso de trasfondo válido que justifique su accionar, consideración que por superficialidad y eficacia ha sido ampliamente difundida por los medios, y posee un sinnúmero de casos en que intervenciones ciudadanas tienden a ser comprendidas simplemente como destrucción de monumentos, obras de arte o cualquier objeto como una manifestación bárbara o carente de sentido, ocultando además su carácter de ciudadanos, en la medida que se clasifican como vándalos.

A modo de ejemplos, de los cerca de 350 casos similares que hemos recopilado de medios de prensa digital e impresa, clasificados y calificados en dichos medios directamente como vandalismo, en los que solo se comunicó y enjuició el acto destructivo sin mayor profundización, tenemos:

Argentina:

- Vandalismo en Buenos Aires a réplica de El Pensador de Rodin, año 2011.

- Vandalismo a estatua de Olmedo y Portales, año 2013.

- Vandalismo a la estatua del General San Martín, en Ushuaia, año 2017.

- Vandalismo en plaza 25 de Mayo, año 2018.

- Vandalismo a bustos de Néstor Kirchner año 2018.

- Vandalismo a esculturas religiosas. Santa Fe, año 2018.

México

- Vandalismo a monumento de los 43 estudiantes de Ayotzinapa, año 2016.

- Vandalismo a monumento en honor a caídos en Nochixtlán, año 2017.

- Vandalismo a monumento a Moctezuma, año 2017. 
- Vandalismo a Esculturas Colonia de Roma, año 2017.

- Vandalismo a Cruz del Migrante, año 2017.

- Vandalismo a estatua de Alfredo del Mazo, año 2018.

- Vandalismo a Monumento de General José María Yánez, año 2018.

- Vandalismo a Monumento de Don Benito Juáreza, año 2018.

- Vandalismo a monumento a Cuauhtémoc en Matamoros, año 2018.

- Vandalismo a monumento a la independencia en Ciudad de México, año 2019.

Perú

- Vandalismo a monumento dedicado a Pedro Huillca, líder sindical peruano, año 2013.

- Vandalismo a monumento del expresidente Manuel Candamo, año 2015.

- Vandalismo a estatua de Micaela Bastidas, año 2017

Uruguay.

- Vandalismo a estatua de Luis Juárez, año 2017.

Chile

- Vandalismo a memorial de Jaime Guzmán en Osorno, año 2008.

- Vandalismo a estatua del Roto Chileno en Arica, año 2015.

En la mayoría de estos casos, considerando los factores expuestos, se podría reconocer un discurso de trasfondo que dé a entender por lo menos las motivaciones que les mueven, y en los casos más complejos u ocultos, se podrían develar apelando a reconocimientos fenomenológicos, sociales o culturales para entender el motor de dichas intervenciones. Como exponíamos antes, ambas manifestaciones de la destrucción del arte, iconoclastas y vandálicas, poseen un eje de funcionamiento, un punto de partida o apuntan a una respuesta determinada por una causalidad específica, pero en la actualidad su conformación y surgimiento, así como los procesos y limitantes que las motivan, son velados, enfatizando lo vandálico para aquellos actos no oficiales y ocultando lo iconoclasta, bajo amparo legal, en decisiones gubernamentales que se manifiestan por medio de erradicaciones, desplazamientos, instauración de monumentos o incluso descuido de ciertas figuras poco convenientes a la administración de turno.

En relación con el primer grupo expuesto, tenemos como ejemplo la intervención realizada en Chile en la ciudad de Arica el 8 de marzo de 2015, en que el monumento al "Roto chileno", héroe popular de la guerra del pacífico, fue travestido y renombrado como "La Rota". Situación que en la prensa fue ampliamente catalogada como vandalismo, pero que atendiendo al contexto de ejecución; marcha del día de la mijer, ejecutante; grupo feminista, la figura representada; un sujeto popular masculino enaltecido como béroe, y la transformación realizada; travestismo, dan cuenta de una percepción crítica que parte de la comunidad tiene sobre su historia, y del dominio total de los referentes monumentalizados en el que, en este caso, se hace evidente el silenciado rol de la mujer en la historia bajo los discursos que respaldaron los privilegios masculinos. Así, al no existir un monumento a la mujer, ni siquiera a la mujer del obrero o del soldado, se toma un monumento existente y se cambia su sentido, resignificándolo, pero no en base a su destrucción absoluta, sino que dotándolo del discurso crítico que se esboza, generando un nuevo monumento, que, aunque momentáneo, da cuenta tanto de lo enaltecido como de lo silenciado. 
Otro caso que se articula de modo similar y que también fue enjuiciado como vandalismo, y en el que se pudiese haber aplicado un análisis simple para su comprensión, son las intervenciones realizadas en Santa Fe, Argentina, en el año 2018, en que objetos religiosos e históricos fueron intervenidos con pañuelos verdes, anexando a ellos las posturas a favor del aborto en discusión en ese momento, tal como sucedió en 2019, en México, en el llamado por la prensa; "Terremoto Feminista".

Desde una relación histórica anterior, pero sobre los mismos mecanismos, tenemos diferentes actos en que se han intervenido, destruido o decapitado esculturas referentes a la colonización, como el caso del monumento a Cristóbal Colón en Perú y en Venezuela en 2016, la decapitación del mismo en Chile, en la revuelta de Octubre de 2019 y en Boston en Mayo-Junio del 2020, en las manifestaciones contra el racismo luego del asesinatos de George Floyd, y de modo similar los monumentos a Pedro de Valdivia por mano de comunidades Mapuches y posterior postura de su cabeza en manos del monumento a Caupolicán en ese mismo contexto. En casos como estos -será solo cuando el contexto desborda de información referente al acto, y la ciudadanía es consciente de las motivaciones que mueven la destrucción-, que los medios comunicarán aspectos complementarios y los gobiernos tomarán consideraciones como no restaurar dichos monumentos o bien sacarlos definitivamente del sitio público. Por ejemplo, en actos anteriores, en que fueron intervenidos monumentos a la conquista, fueron en su totalidad clasificadas como vandalismo y adjudicada a vándalos o a delincuentes, pero en dominio contextual, por ejemplo las revueltas de Octubre en Chile, las clasificaciones cambiaron: se comienzan a utilizar conceptos como derribar o erradicar y al sujeto ejecutor se le considera como manifestante, se anexa la relación al pueblo mapuche y se contrastan los elementos que dan pie al acto destructivo. Situación que se presentó de modo similar en las manifestaciones contra el racismo en Norteamérica y Europa, en las que si bien no se valida el acto destructivo se otorgan y comunican más herramientas para su comprensión en la medida que el contexto se nutre de referentes históricos y sociales, lo cual se posibilita solo en momentos de conflicto declarado, pero que en la cotidianeidad tienden a ocultarse y a silenciarse.

Para apuntar a un manejo competente y lograr evidenciar los mecanismos que mueven estos actos, aún en situaciones no declaradas de conflicto, y lograr comprenderlas y comunicarlas como manifestaciones específicas provenientes de una comprensión histórica y de una evidente relación critica de los sujetos con el espacio público, se torna necesario el organizarlas en diferentes categorías que permitan un análisis competente o que al menos integren mayores elementos a su comunicación, rompiendo con el calificativo de vandalismo como una herramienta de medida y análisis de dichos actos. Como el interés principal tiene que ver con la construcción o destrucción de monumentos públicos, que es lo que se hace evidente, serán estos mismos aspectos los que facilitarán su manejo, será el ejercicio constructivo, destructivo o reconstructivo el que permitirá un acercamiento competente a manifestaciones de un fenómeno reconocible en diversos momentos de la historia latinoamericana. Existen, en este sentido, una serie de formas en que los distintos grupos humanos interactúan sobre el arte y monumentos públicos, no siempre serán estas evidentes al punto de la desintegración, tendrán en su mayoría otras formas de ejercicio condicionada por las posibilidades de intervención y por los recursos legales de respaldo; las que van desde daños, descuido, mutilación simbólica, atentados, intervención, rayados y transformación, llegando incluso hasta el desplazamiento y descentramiento, los que comparten un fuerte carácter simbólico en su ejecución y traen consigo la respuesta silenciada a un discurso muchas veces impuesto. Categorías que expondremos a continuación junto algunos casos recopilados a modo de ejemplo.

\section{Monumentos descuidados}


Una de las formas más numerosas de destrucción -que, si bien es menos evidente en su funcionamiento, pero igual de efectiva- es el descuido al que se someten algunos monumentos. El descuido y no mantención de monumentos públicos atenta y va en contra de las disposiciones de los distintos consejos de monumentos en Latinoamérica, los que desde diferentes posturas establecen como misión el velar por el cuidado y mantención de monumentos públicos, por tanto el descuido de estos se comprende incluso, más allá de una negligencia e incumplimiento de normas, sino que se puede llegar a reconocer -en algunos casos- como una forma de supresión de monumentos que no implica un compromiso ideológico directo o evidente, considerando que existen departamentos encargados de salvaguarda y mantención, se destinan recursos para ello y principalmente debido a que se rompe con la idea de permanencia en el tiempo de un monumento, la que busca fijar en lo público una perspectiva histórica particular. En este sentido, es posible advertir la no-acción como una forma de respuesta ante la validez que tiene para las autoridades la figura rememorada, lo cual se podría reconocer identificando la relación entre la postura política del gobierno de turno y la postura política de la figura representada o de quienes erigiesen dicho monumento y generar un contraste que permita evidenciar lo que la vuelve una acción no prioritaria e incluso compararla con ejercicios sobre monumentos que estén en la línea discursiva y política gubernamental. A modo de ejemplos en los que se podría advertir, aunque lamentablemente no comprobar en todos los casos esta manifestación, tenemos:

Chile:

- Descuido y destrucción de la plaza Víctor Jara de Pudahuel, año 2013.

- Descuido y destrucción del memorial a las mujeres víctimas de represión en dictadura, año 2014.

Colombia:

- Descuido y no mantención monumentos del puerto, año 2016.

Perú:

- Destrucción y no mantención de Estatua de La Libertad. Plaza Francia, año 2002.

- Destrucción y no mantención de Monumento al Libertador San Martín, año 2002.

- Destrucción y no mantención de Monumento a Pizarro, año 2002.

- Destrucción y no mantención de Monumento al mariscal Andrés A. Cáceres, año 2002.

- Destrucción y no mantención de Monumento a Manco Cápac, año 2002.

- Destrucción y no mantención del retrato de Chabuca Granda, año 2002.

\section{Monumentos erradicados y propuestas gubernamentales de desmonumentalización}

En la forma más radical de esta categoría, tenemos las manifestaciones que buscan la destrucción directa y erradicación de un monumento, lo que apunta a "eliminar todo rastro (...) y de la intención que hubo detrás de su creación e instalación"46 de dichas obras. En general estas acciones son manifestadas por el Estado en momentos en que las políticas son más estrictas en cuanto a supresión ideológica y se posibilita la erradicación de monumentos, sin reproche directo y sin la necesidad de adaptarse a normativas de resguardo, por lo que suelen ser menos las reconocidas. Un ejemplo de esto, de los tantos presentes en periodos dictatoriales, es el caso del Monumento a Ernesto Guevara,

${ }^{46}$ Gamboni,Darío, Teorías y métodos..., op. cit., pág. 29. 
quizás el primer monumento erigido a esta figura, instaurado durante el gobierno de Salvador Allende en Chile, dinamitado y eliminado en septiembre de 1973 con la instauración de la dictadura.

En periodos sin conflictos declarados y sin políticas totalitarias, las autoridades deben tomar otros medios de supresión que van desde la no-mantención antes señalada a las propuestas de desmonumentalización, en las que se busca seguir un camino legal para desplazar o erradicar determinados referentes simbólicos del espacio público, suprimiendo figuras que supuestamente no están acorde a la comunidad en la que se erigen, o bien desplazando a espacios urbanos periféricos las figuras instauradas en centros de importancia o de gran flujo de personas. A modo de ejemplo de estas manifestaciones tenemos:

Argentina:

- Propuestas de demolición del monumento al Che Guevara, año 2008.

- Monumento a Juana Azurduy reemplaza a monumento de Colón, año 2012.

- Conflictos alrededor de los monumentos al Gral. Roca en Buenos Aires y San Carlos de Bariloche, año 2012.

- Traslado de Monumento a Cristóbal Colón, desde Casa Rosada a Mar del Plata, año 2012.

- Traslado de monumento a Juana Azurduy de Casa Rosada a la plaza frente al CCK, año 2017.

- Imputación al intendente de Morón por no restituir el busto de Néstor Kirchner, año 2018.

- Municipalidad de Neuquén retira monumento a General Roca, año 2019.

Bolivia:

- Polémicas por monumento a la revolución, año 2012.

- Polémica por inauguración de estatua a Hugo Chávez, año 2014.

Chile:

- Propuestas de cambio de nombres de calles y plazas alusivas al golpe de estado chileno de 1973, 2000-2018.

- Propuesta de representantes de la derecha por declarar la casa de Augusto Pinochet Monumento Nacional, año 2007.

- Propuesta para instaurar monumento a Pinochet en la plaza de la constitución.

- Propuesta de demolición plaza Víctor Jara de Pudahuel, año 2017.

- Propuesta de la derecha para desplazar el monumento a Salvador allende de la plaza de la constitución, año 2017.

- Corte de apelaciones de Santiago ordena sacar placas alusivas a la Dirección de Inteligencia Nacional (DINA), Santiago año 2019.

Colombia:

- Propuesta de creación de monumento con armas de las Fuerzas Armadas Revolucionarias de Colombia (FARC) , año 2017.

- Propuesta de reconstrucción monumento de la Carrera 66, año 2017.

Ecuador:

- Erradican monumento a los Héroes del Cenepa, año 2012.

- Instauración de Monumento a Kirchner en plaza Argentina, año 2014. 
- Alcaldía de Quito retiró el monumento de Néstor Kirchner, año 2018.

Nicaragua:

- Polémica por monumento a Chávez, gobierno de Artega, año 2013.

\section{Ataques o atentados a monumentos}

Otra forma de erradicación de monumentos, pero en su vertiente no legal, lejos de la oficialidad y del resguardo del Estado, son los intentos por destruir y erradicar monumentos, los que, al no poder eliminarse a través de la vía legal, se intentan suprimir por medio de vías mucho más radicales, intentos que, en su mayoría, por causas de las políticas públicas, son considerados y difundidos en los medios como actos de terrorismo. Un ejemplo de esto en Chile fueron; el intento del Movimiento de Izquierda Revolucionaria (MIR) por extinguir -a través del uso de explosivos- la llama eterna de la libertad en su estancia en el cerro Santa Lucia, el 21 de Abril de 1980, en el que fallece el carabinero que la custodiaba, posteriormente en relación al mismo monumento, esta vez en su lugar original, en el Paseo Bulnes, el 19 de agosto del año 2003, miembros del Foro Sociedad Civil atentan contra esta, en un acto menos violento pero igual de significativo, esfuerzo que es evitado por efectivos policiales. De modo similar, tenemos el ataque explosivo del año 2011 y en 2019 al memorial al fundador de la Unión Demócrata Independiente (UDI), Jaime Guzmán. En cuanto al primer monumento, la llama eterna de la libertad, la que dicho sea de paso fue erradicada en 2004 de modo indirecto por medio de una remodelación durante un gobierno de centro izquierda, evidenciamos en distintos momentos de la posdictadura, la necesidad de erradicar lo que esa llama representa, una idea específica y triunfalista de la libertad, y en el segundo caso, del memorial de Guzmán, tenemos un acto que apunta a destacar la importancia y comprensión negativa de la figura de este, como ideólogo de la dictadura, que dicho memorial representa en su inscripción, según la perspectiva de quienes cometen el atentado.

A modo de ejemplo, de otros atentados a monumentos que hemos podido recopilar en América Latina, tenemos:

Venezuela:

- Ataque incendiario a estatua de Hugo Chávez en su ciudad natal, año 2018.

Argentina:

- Atacan Cementerio de Guerra y Monumento a los Caídos en Malvinas de Darwin, año 2012.

- Atentado contra monumento al Che Guevara, año 2017.

- Queman bandera argentina y vandalizan monumento a Malvinas, año 2017.

Bolivia:

- Atentado explosivo contra monumento del Mártir Pedro Domingo Murillo, año 2007.

- Atentado destruye monumento a héroe boliviano de alzamiento contra España, año 2009

- Atentado destruye monumento a Pedro Domingo Murillo ,en Chulumani, año 2009.

\section{Monumentos mutilados o destruidos parcialmente}

Centrándonos también en la vereda de las manifestaciones no legales, clasificadas normalmente como vandalismo, tenemos la mutilación simbólica o la destrucción parcial de monumentos. Como señala Gamboni, una obra "puede ser "dañada" y no "destruida” con el fin de convertirla en una 
muestra de la violencia a [la] que ha sido sometida y de la infamia de aquello con lo que se la relaciona" ${ }^{47}$, así, importa el resignificar el espacio apropiado por el emisor del mensaje, partiendo de la aceptación de la incapacidad de disponer libremente sobre el destino del monumento, ya que se acepta que el monumento forma parte del contexto en que se ha instaurado, y se acepta de paso su rol estético y de trasmisión de significado. Es por este motivo que se busca aprovechar la misma plataforma como un espacio para romper con ese discurso cerrado, resignificándolo, otorgándole al monumento una doble función, que contiene la percepción triunfalista sobre la figura histórica de quienes emiten el mensaje y la percepción crítica de quienes ejecutan la mutilación, transformándose este en un nuevo monumento que representa la respuesta ante dicha imposición. El carácter simbólico de la mutilación o destrucción parcial de un monumento -sobre todo en el caso de las decapitaciones de estos-, conlleva un mensaje de respuesta que a duras penas es posible ocultar bajo el calificativo de vandalismo y que puede ser percibido directamente por los grupos que instauran un monumento y por la ciudadanía, confluyendo en torno a este diferentes mensajes y posturas, otorgándole de cierta forma un carácter democrático-disruptivo.

A modo de ejemplos, tenemos la decapitación del monumento al Che Guevara en Venezuela en los años 2007 y 2008, la mutilación de las piernas de la estatua de Messi en Buenos Aires, en 2017, las reiteradas decapitaciones y destrucciones a los monumentos a Jaime Guzmán, en 2005, 2009, 2016 y 2019 en Chile, la decapitación y destrucción en distintos puntos del continente de bustos y esculturas de Cristóbal Colón; en Venezuela el año 2004, Perú en 2016 y 2017, Chile en 2019 e incluso en EEUU en 2020. Manifestaciones en las cuales es posible identificar posturas en oposición que responden de modo crítico por medio de la decapitación o destrucción simbólica de símbolos impuestos en el espacio público.

De modo similar, tenemos otras manifestaciones o destrucciones parciales, que podrían contenerse dentro de esta categoría, ejemplos en que es posible reconocer esa inversión del sentido de la obra, motivados por la unidireccionalidad del mensaje, con un trasfondo político que, en estos casos, obedece a la selección de íconos que no representan quizás a toda la población que habita el espacio en que el monumento se instaura, o que bien, carecen de actualización en cuanto a los intereses de una comunidad.

Argentina:

- Destrucción en La Plata del monumento que recuerda a Rodolfo Walsh, año 2014.

- Destruyen monumento conmemorativo a la masacre de Luna Roja, año 2014.

- Destrucción de estatua de loba romana en parque Ledezma, año 2015.

- Destrucción del monumento en homenaje al día de la heroicidad, año 2016.

- Destrucción de la escultura del poeta Horacio Ferrer en Avenida de Mayo, año 2017.

- Destrucción de monumento dedicado a los bomberos, año 2017.

- Destrucción del monumento a los caídos de Malvinas en Neuquén año 2017.

Chile:

- Destrucción del monumento a Violeta Parra en Chiguayante, año 2012.

- Destrucción de la plaza Víctor Jara de Pudahuel, año 2013.

- Destrucción del memorial a las mujeres víctimas de represión en dictadura, Santiago, año 2015.

- Busto decapitado de Jaime Guzmán, en la ciudad de los Ángeles, año 2016.

${ }^{47}$ Gamboni,Darío, Teorías y métodos..., op. cit., pág. 29. 
- Decapitación de los bustos a los héroes de la Guerra del Pacífico en Arica, año 2017.

Colombia:

- Destrucción de la placa de homenaje a Vernon en Cartagena de Indias por artista, año 2014.

- Destrucción monumento al porro en la Plaza Cultural del Sinú, año 2018.

Ecuador:

- Destrucción de monumento "Los Caballos de Endara", año 2006.

- Destrucción de monumento "El Toro", año 2006.

- Destrucción de monumento "El árbol", año 2006.

México:

- Destrucción monumento "La Estampida” en Navaja, año 2017.

- Destrucción de monumento a la independencia, año 2018.

Nicaragua:

- Decapitan monumento a José Martí, en Nicaragua, año 2018.

Perú:

- Mutilación a Monumento al coronel Francisco Bolognesi, año 2001.

\section{Monumentos rayados o intervenidos}

Al verse limitados los medios de relación y comunicación del sujeto con el poder y los discursos oficiales, y más aún en el caso de un discurso impuesto y cerrado como el de los monumentos, las alternativas existentes, consideras en este caso como vandalismo, se presentan como recursos accesibles a una parte no menor de la población, en este sentido las "prácticas infra políticas de acción vandálica" 48 obedecen a un proceso de adecuación entre las limitaciones del medio y los recursos reales a los que se tiene acceso. Prácticas en que las proyecciones no tienen miras muy significativas, es decir, no obedecen a un plan estructurado, sino a una respuesta fenomenológica, así "no se hipoteca la posibilidad de acción a la espera de mayores fuerzas, [como el caso antes expuesto de los atentados] ni a la expectativa de mayores resultados: su máxima condición es la posibilidad que ofrece el momento" ${ }^{\prime 49}$ pues se reconoce -consciente o inconscientemente- el lugar que se tiene frente al discurso que el poder esboza.

Una de las maneras más fáciles, directas o cercanas, de atacar un monumento y principalmente menos oficial, es la de rayarlos o intervenirlos. En el acto del rayado al monumento, se intenta adherir al discurso cerrado que manifiestan, un mensaje adicional que complementa el discurso unilateral que el monumento esboza. No se espera que el monumento desaparezca o no se apunta directamente a su destrucción, el intento obedece principalmente a la necesidad de resignificación y apropiación del recurso, en cuanto a que está situado en el espacio público en directa relación con los sujetos que manifiestan la conciencia que el monumento busca interpelar.

Si partimos de la base de que el monumento busca identificar y representar a la ciudadanía con determinados valores, o con un pasado histórico concreto, comprendemos que el rechazo a estas se plantea en el desconocimiento y el no reflejo -o introyección- de dichos valores. El monumento en

48 Sánchez, Mario Jordi y Aix Gracia, Francisco, "Vandalismo contra el patrimonio...", op. cit., pág. 6.

49 Sánchez, Mario Jordi y Aix Gracia, Francisco, "Vandalismo contra el patrimonio...", op. cit., pág. 6. 
cuestión no posee por tanto una carga simbólica suficiente que identifique a la totalidad de sujetos que se relacionan con este, por este motivo se busca dejar una marca, agregar un sentido, otorgar nuevas líneas de representación al discurso monumentalizado, se busca agregar parte de sí mismo, y su percepción de mundo y su comunidad "sobre los objetos como demostraciones de ejercicio del poder" ${ }^{20}$. Una forma directa de hacerlo es con intervenciones rápidas, accesibles, que no impliquen una organización específica de base o una planificación, en su mayoría obedecen a casos dados en momentos en que se facilita dicha interacción.

En esta categoría, es posible reconocer diferentes manifestaciones de dichos actos, las que hemos organizado según el sentido del mensaje anexado, rompiendo con la clasificación generalista y única de vandalismo, atendiendo a la relación entre mensajes en oposición. Así clasificamos estas en; rayados con motivos de problemáticas sociales, políticas y religiosas. Si bien estas categorías obedecen en suma a la consideración general de motivos sociales, esta subclasificación puede ayudar a facilitar su manejo.

En esta oportunidad, por temas de manejo y espacio, nos centraremos en algunas manifestaciones del caso chileno, pues al no ser de interés de toda la prensa del continente el comunicar dichos mensajes anexados, sino tan solo el acto de vandalismo, por ello ha sido más fácil acceder de modo directo, por cercanía, a las manifestaciones del caso chileno y a las de otros países, que listaremos al final, por medio muchas veces de prensa alternativa o difusión en redes sociales.

\section{Rayados con motivos sociales}

Primero, en cuanto a rayados o intervenciones con motivos sociales, tenemos el encapuchamiento del monumento a los enamorados de Puerto Montt, en el año 2011, en el contexto de las movilizaciones estudiantiles, en el que se pintaron pasamontañas a uno de los monumentos más significativos de dicha ciudad, acto con el que se transformó momentáneamente un monumento que hace alusión a la cultura popular de la zona: -al hombre, a la mujer y al amor-, en directa interpelación con la lucha estudiantil, involucrando así a los elementos representados. Otro caso es la intervención a los bustos de los héroes de la guerra del Pacífico, en marzo de 2015, en el contexto de movilizaciones feministas en el norte de Chile, en cuya intervención es posible leer "Mártires, bájense de sus pedestales, que las feministas venimos a luchar", dando cabida al rol de la muer en la luchas sociales. En el mismo contexto, tenemos la intervención antes mencionada sobre el monumento Al Roto chileno de Arica, en la que aparte del acto de travestismo se anexó el mensaje: "La Rota: para ser valiente hay que ser mujer", en ambas se establece una relación con el monumento en cuanto a la figura masculina enaltecida, reconociendo una apropiación, apelación y reinterpretación del monumento.

Otro monumento intervenido en relación con las movilizaciones estudiantiles es el monumento a Bernardo O’Higgins, de Talca en el año 2016, en que esta figura histórica aparece firmando el acta de independencia, documento al que se le añade en la intervención, "Ley de educación, lean por favor" generando un nexo entre los orígenes de la patria y el estado actual de esta.

\section{Rayados con motivos políticos}

En segundo lugar, en relación con las "crisis de otras formas de interlocución política, [d]espués de la crisis de las grandes ideologías y de los partidos políticos como formas de interlocución”, podemos

50 Sánchez, Mario Jordi y Aix Gracia, Francisco, "Vandalismo contra el patrimonio...”, op. cit., pág. 6.

51 Sánchez, Mario Jordi y Aix Gracia, Francisco, "Vandalismo contra el patrimonio...", op. cit., pág. 3. 
reconocer intervenciones o rayados a monumentos que apelan a la interacción con algunas de estas figuras políticas, llegando a transformarse estos actos de relación, clasificados como vandalismo, en "fórmulas verdaderamente resolutivas de democracia directa" 52 así podemos reconocer a modo de ejemplo de los rayados con motivos políticos actos como las constantes intervenciones sobre la figura de Jaime Guzmán, en los que reconocemos una serie de intervenciones a sus monumentos, como el busto de la ciudad de los Ángeles, en el sur de Chile, que en el año 2014, previo a su decapitación, fue intervenido con el mensaje "sin honores al opresor" con lo que se intenta romper con la lógica monumental por medio de la que se exalta su figura. De modo similar sucedió con la placa conmemorativa a este personaje en Viña del Mar, la que en el año 2015 es rayada con mensajes apoyando su muerte y haciendo referencia al Frente Patriótico Manuel Rodríguez (FPMR), así como los reiterados rayados en el memorial a este personaje, en el cementerio de Santiago en las manifestaciones de conmemoración del golpe de estado.

Como hemos señalado antes, esta forma de interacción con los monumentos no es propia de una tendencia política, sino que tiene que ver con las posibilidades legales de manejo y relación con el monumento, por ese motivo es posible advertir diversas manifestaciones con figuras políticas independiente de su postura. Tal como se ha rayado e intervenido el memorial a Jaime Guzmán, se ha intervenido y rayado el memorial de Allende o diversos rayados sobre memoriales de detenidos desaparecidos en este país.

\section{Rayados con motivos religiosos}

En último lugar de esta subcategoría de rayados con motivos sociales, tenemos los rayados con motivos religiosos, en este punto podemos reconocer tanto, rayados motivados por una ideología religiosa particular o por el rechazo a estas mismas y sus planteamientos. Así, podemos reconocer los rayados al monumento de Bulnes en Santiago, el cual lo representa con unos niños simbolizando el futuro de Chile y en el que se agrega el año 2015 la consigna "que los huecos no adopten niños" sumado a "muerte a los gays" en las rocas que acompañan dicha obra. Acción en la cual reconocemos el intento de plantear rechazo a las políticas de matrimonio igualitario y unión civil que estaban en discusión en aquel momento. Por el otro lado de la vereda, unos años antes, tenemos rayados en monumentos religiosos, que en la catedral de Santiago el año 2013 que aludían a consignas contra el aborto con mensajes como "María quería abortar".

A modo de complemento de los casos chilenos expuestos, anexamos también algunos ejemplos en otros países latinoamericanos:

Argentina:

- Rayan Monumento al Che Guevara, año 2016.

- Rayados a monumento del holocausto judío, año 2017.

- Rayados e intervención a monumento de Néstor Kirchner, año 2018.

- Rayados e intervención a monumentos en marcha a favor del aborto, año 2018.

- Rayados e intervención de monumentos religiosos en Santa Fe, en marcha proaborto, año 2018.

Venezuela:

- Rayan Busto de José Antonio Páez, año 2017.

52 Sánchez, Mario Jordi y Aix Gracia, Francisco, "Vandalismo contra el patrimonio...”, op. cit., pág. 3. 
- Rayan Monumento a Cristóbal Colón, año 2016.

Uruguay.

- Rayan Monumento al Holocausto Judío, año 2017.

México:

- Rayados a monumento de Bolívar en Villa Hermosa, año 2017.

Perú

- Rayados a monumento histórico Paseo Colón, año 2016.

- Rayados a muro inca de Machu Pichu, año 2016.

- Rayados a monumento histórico en Perú, año 2017.

- Rayados a estatua de Cristo regalada por Odebrecht, año 2017.

- Rayados a monumento histórico Paseo Colón, año 2017.

- Rayados a templo inca de Coricancha, año 2017.

En todas las categorías expuestas sobre rayados a monumentos, las cuales son una de las más comunes en distintos centros urbanos, podemos reconocer la necesidad de interpelar al monumento, la necesidad de romper con un discurso no dialógico en que se impone una postura. La ciudadanía, al estar privada de recursos y posibilidades de monumentalizar sus propios referentes simbólicos, o erradicar otros, debe buscar alternativas de relación en la medida de las posibilidades y recursos que posee.

\section{Conclusiones}

En lo planteado en estas páginas, se ha apuntado principalmente a comprender en qué medida la instauración de arte monumental obedece al intento, oficial o social, de erigir y establecer en el presente marcas de un pasado específico rememorado, en busca de que estas figuras o simbolismos particulares, dejen huella no solo en la historia de sus grupos, sino que pasen a formar parte de la conciencia e identidad ciudadana y de la memoria colectiva, en la medida que se establecen como referentes directos y reconocibles en la cotidianeidad. En este proceso se ha podido identificar que la instauración de monumentos ha obedecido históricamente a un ejercicio de poder, en el que a través del acto de dominio del espacio público, se instauran monumentos que en su carácter marmóreo, de piedra, comprendidos como discursos cerrados, no dan pie a un carácter dialógico que permitan puntos de vista diferentes entre emisores y receptores. Ante esta limitante los grupos ciudadanos, e incluso el mismo poder en ejercicio, se valen de diferentes medios y métodos para poder interactuar, resignificar, o incluso destruir las figuras e ideas y el carácter político e ideológico que estos monumentos traen consigo. Es en esta pugna donde reconocemos que las clasificaciones y el dominio de la opinión pública, y los medios de comunicación, son fundamentales en el proceso de validar y clasificar unos actos por sobre otros, en relación con la transformación, instauración o erradicación de monumentos. Siendo generalmente validados en su manifestación iconoclastas los actos que permitan una justificación estética, cultural o social de fondo para su destrucción o transformación, -siempre y cuando dicha explicación tenga cabida en el discurso oficial-, y relegando a la clasificación de vandalismo a todas aquellas manifestaciones sobre el arte monumental, que no tengan cabida ni lógica en relación con el discurso oficial reconocido y que por lo tanto se presentan como invalidas, erróneas y disruptivas. 
En este sentido, siguiendo en estricto rigor las clasificaciones de iconoclasia/vandalismo discutidas, planteamos que el carácter de iconoclasia, eje de validación de algunos actos, es aplicable a todas las realidades y relaciones del sujeto con el arte monumental. Si comprendemos que la diferencia entre ambas está simplemente en la explicación y justificación de sus motivos, sumado a la validación de unos discursos por sobre otros, podríamos incluso determinar que no existe movimiento social, acción o relación con el medio que no se reconozca como respuesta a una lógica determinada o a un factor sociocultural que le motive, cuya comprensión o análisis permitirá la explicación de los fenómenos que justifican su ejecución. El foco de atención, estará entonces, en que los proyectos estructurados- de fondo son el punto diferenciador entre unas y otras, siendo relegadas las manifestaciones que proceden como respuestas tanto a la unidireccionalidad de estos mensajes, como a las políticas públicas que los erigen -oficialmente- en uno u otro momento de la historia, con el vaivén de ejercicios del poder presentes.

El principal elemento diferenciador es lo que podríamos llamar la democratización de la iconoclasia, pues los ejercicios iconoclastas ya no son propios de cúpulas de poder -aunque siguen existiendo sobre todo en ejercicios de monumentalización y desmonumentalización-, sino que pueden ser manifestados por cualquier sujeto o colectivo que comprenda una situación disruptiva entre el ícono, el espacio en que se sitúa y sus propios intereses o perspectivas.

No tratamos aquí de validar el vandalismo, en su sentido rudimentario, como una forma sana de relación del sujeto con el entorno, ni apuntamos a catalogar cada acto de vandalismo como una respuesta iconoclasta, sino que buscamos evidenciar que tras ese acto o discurso, catalogado como delito o como incorrecto, es posible advertir una sintomatología evidente que requiere replantear las formas de manejo y comunicación de estos, para así comprender que detrás de ellas existen motivaciones que están determinadas, aun sin una articulación evidente, por las posibilidades y carencias que las comunidades poseen. Momentos en que, aun de forma rudimentaria reflejado en sus actos, los sujetos reconocen el discurso monumental como una herramienta de imposición ideológica y de dominación del espacio público, que no contempla a todos los habitantes de un espacio y que no es capaz de actualizarse en relación a los intereses y formas de comprensión del pasado y presente de una comunidad. Lo que de paso da cuenta de ciudadanos críticos que comprenden los símbolos y signos que se erigen en los espacios que habitan y establecen posturas particulares o comunes frente a ellos.

En este sentido, y siguiendo esta línea, para finalizar, apuntamos a mirar en profundidad las diferentes formas de relación de los sujetos con su entorno, sin minimizarlas ni restarles importancia o trasfondo, por más radicales que estas sean. Pues, sería impreciso e insuficiente el abordarlas como hechos aislados que no proceden de motivaciones previas y que no poseen un sentido concreto que se evidencia incluso en el acto destructivo. Tomando en consideración, como antes se mencionaba; el contexto de ejecución, el ejecutante, la figura representada y su incidencia histórica en el contexto, como herramientas de lectura de la transformación o intervención realizada. Podemos llegar a comprenderlas incluso, al nivel de manejo de manifestaciones artísticas con una clara mediación estética y cultural de base.

Es necesario replantear, por tanto, las formas en que comprendemos y comunicamos estas manifestaciones, en pos de la construcción de espacios en que coexistan diversas perspectivas y formas de relación, y asimismo buscar herramientas que permitan la inclusión total de la ciudadanía y la actualización de los aspectos materiales-simbólicos, en concordancia con los actuales cambios ideológicos y de comprensión del pasado y presente las comunidades. 


\section{Jonathan Lukinovic Hevia}

Es Licenciado en Letras con mención en Literatura, Magister en Literatura Latinoamericana y Chilena y Doctor en Estudios Americanos del Instituto de Estudios Avanzados de la Universidad de Santiago de Chile. Este artículo se enmarca en su proyecto doctoral "La guerra de los monumentos: respuestas iconoclastas ante la imposición cultural y dominio ideológico del espacio público en América Latina". Docente de la Universidad Autónoma de Chile. Autor de los libros: "La canción Punk de los años 80 en Chile", "El Tiempo del Miedo" y de "Sexta punk: 255 afiches de historia". Director de la cooperativa cultural El Ingenioso Taller desde el año 2015 y de Editorial Camino desde el 2016. 